\title{
COPD: A common disease that is preventable and treatable
}

In this issue of the Primary Care Respiratory Journal, a new paper on the diagnosis of respiratory diseases in primary care [1] highlights the need for greater awareness of chronic respiratory diseases in primary care and is a call to action for the primary care community. It follows the publication of the International Primary Care Airways Group (IPAG) Handbook on the Diagnosis and Management of Chronic Airways Diseases published in January 2005 [2], and is accompanied in this issue by the IPCRG Guideline paper on the managemsnt of chronic obstructive pulmona y aseane (EOPD) in primary care [3] "Th? /PAG handbook [2] anc these two IP(BCG Guidelwe papors $[1,3]$ have been written for, and by, primary care phiysicians.

Primary care providers look after most patients with COPD, at least until they have very severe or end-stage disease. Recent reliable prevalence estimates for COPD indicate that, in many countries, up to a quarter of the population over the age of 40 has some degree of COPD (or irreversible airflow obstruction) [4], and that the prevalence in women and men is about the same in countries in which smoking habits are about equal. The prevalence increases strikingly with age. In developing countries, the prevalence is still appreciably higher in men than women, reflecting the sex difference in smoking that still exists in many countries. However, this situation is changing since women are being actively targeted by global tobacco companies keen to expand their markets in developing countries. The expected consequence of this is that the prevalence of COPD will soon be equal in men and women worldwide, and will increase steadily as life expectancy increases.

Equally remarkable are the consistent findings from several countries that less than half of those patients with COPD have been diagnosed $[5,6]$. There is also a gender bias in the diagnosis of COPD, with men more likely to resei $e$ thedisgriosis than women [7].

Whr is this? It's hard to know why we are doing Cuch a poor job of delecting a disease which is so commion, whict can be diagnosed easily, and Whic? has treatments readily available to improve patients' quality of life. Using the analogies of hypertension or diabetes, for example: no clinician would dream of treating either of these conditions without first establishing the diagnosis using the appropriate diagnostic tests, and then monitoring the treatment response and disease progression with objective tools such as blood pressure monitoring and blood tests. Yet, less than $20 \%$ of patients with COPD or asthma receive spirometry to diagnose their disease, and long-term management of both diseases is more often than not done in the complete absence of any objective measure of lung function. This is remarkable and puzzling.

It is easy to blame the clinician for these shortcomings. Perhaps more constructively, one can look at the barriers and try to find solutions. Why is COPD so under-diagnosed and under-appreciated? Firstly, the patient may interpret their symptoms of slowly-increasing 
shortness of breath, fatigue, cough and wheezing, as being simply due to ageing, and they may not even mention them during routine visits - or come to see a clinician because of them. If symptoms are mentioned, and the patient is a smoker, the usual assumption is that the symptoms are due to smoking and that the treatment is to stop smoking. Given the generally negative attitude of physicians towards COPD, there may be no further attempts made to make a diagnosis and management plan.

Secondly, the role of spirometry in helping to make the diagnosis of COPD and a subsequent management plan, appears to be poorly understood. The barriers to doing spirometry testing are: lack of time; lack of familiarity with the tests (which ones to order and how to use the results); lack of access to spirometry; and the cost of the equipment. All national and international guidelines recommend the use of spirometry, both to make the diagnosis of COPD and to manage the disease. The barriers no longer make sense since inexpensive, robust, and easy-to-use spirometers are now available, and since built-in quality control software helps to ensure that the data are reliable and easy to interpret. We should encourage the use of spirometry in all patients who present with exposure to COPD risk facters siloking, occupational particulates and in aoor air pollution being the most colng iur - and/or svmitonis d cough, sputeurn and dyspnoez. Spilcrnetry should be done before and after 2.4 puffs of an inhaled short-acting bronchodilator (e.g. salbutamol) since the definition of COPD is irreversible airflow obstruction. A post-bronchodilator FEV1/FVC ratio of $<70 \%(0.7)$ is consistent with a diagnosis of COPD [8-10].

To raise the profile of COPD management amongst primary care clinicians, several initiatives are presently underway. Perhaps the most far-reaching of these is the Global Initiative for Chronic Obstructive Lung Disease (GOLD) $[8,9]$, a program that includes globally-relevant guidelines for the diagnosis and management of COPD, as well as an active dissemination program now available in 46 countries on www.goldcopd.org. The GOLD Initiative has primary care practitioners in both the Executive Committee, and as GOLD National Leaders. The unique aspect of the GOLD Initiative is that the management portion of the guidelines is updated annually to incorporate the most recent science, with updates being posted on the GOLD web site. The most recent update (September 2005) included relevant papers that were published in 2004 [8], and included an expanded section on the use of antibiotics in COPD exacerbations that provides practical guidance about which antibiotics are most effective in this setting.

The two IPCRG Guideline papers in this issue $[1,3]$ are based on the GOLD guidelines, and they give clear practical guidance for primary care clinicians on the diagnosis and management of COPD with particular emphasis on the importance of spirometry testing. They constitute an important additional initiative which, if implemented carefully, will vastly improve the management of COPD in primary care.

\section{References}

[1] Levy ML, Fletcher M, Price DB, Hausen T, Halbert RJ, Yawn BP. International Primary Care Respiratory Group (IPCRG) Guidelines: Diagnosis of respiratory diseases in primary care. Prim Care Resp J 2006;15(1):20-34.

[2] The International Primary Care Airways Group (IPAG). Diagnosis and management handbook. Chronic airways diseases: A guide for the frimer. Chre physician. Jan 2005. MCR Vision Iric. Als avilable at URL; http: / /www. ipagguice or! $/$. V

Beliamy D, Henrichsen S, Johansson G, et al. International Primary (Care - Pesfiratory Group (IPCRG) Guidelines: Maragentent be Chronic Obstructive Pulmonary Jiscase (COPD). Prim Care Resp J 2006;15(1): 48-57.

[4] Menezes AMB, Perez-Padilla R, Jardim JR, Muiño A, Lopez MV, Valdivia G, Montes de Oca M, Talamo C, Hallal PC, Victora CG. Chronic Obstructive Pulmonary Disease in Five Latin American Cities (the PLATINO study): A Prevalence Study. Lancet. Published online November 4, 2005.

[5] Fukuchi $Y$, Nishimura $M$, Ichinose $M$, et al. COPD in Japan: The Nippon COPD Epidemiology Study. Respirology 2004;(9):458-65.

[6] Mannino DM, Gagnon RC, Petty TL, Lydick E. Obstructive Lung Disease and Low Lung Function in Adults in the United States: Data from the National Health and Nutrition Examination Survey, 1988-1994. Arch Intern Med 2000;160(11):1683-9.

[7] Chapman KR, Tashkin DP, Pye DJ. Gender Bias in the Diagnosis of COPD. Chest 2001;119(6):1691-5.

[8] Global Initiative for Chronic Obstructive Lung Disease. Global Strategy for the Diagnosis, Management, and Prevention of Chronic Obstructive Pulmonary Disease. National Institutes of Health, National Heart, Lung and Blood Institute; April 2001 (updated 2005). Available at URL: http://www.goldcopd.com.

[9] Pauwels RA, Buist AS, Calverly PMA, Jenkins CR, Hurd SS. Global Strategy for the Diagnosis, Management and Prevention of Chronic Obstructive Pulmonary Disease. Am J Respir Crit Care Med 2001;163:1256-76.

[10] Celli BR, MacNee W, committee members. Standards for the Diagnosis and Treatment of Patients with COPD: A Summary of the ATS/ERS Position Paper. Eur Respir J 2004;23: 932-46. 
Sonia Buist*

Pulmonary and Critical Care Medicine, Oregon Health and Science University, Mail Code UHN67, 3181 SW Sam Jackson Park Road, Portland, USA
* Tel.: +1 5034945791 .

E-mail address: buists@ohsu.edu

1 December 2005

Available online at www.sciencedirect.com

Science 0 DiREct

Available online at http://www.thepcrj.com

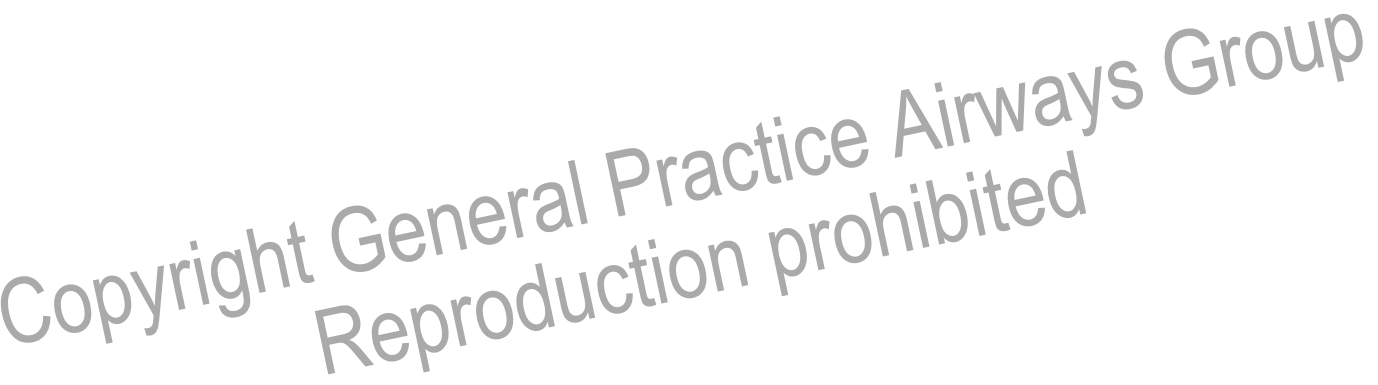

